\title{
Determination of complex dielectric functions of ion implanted and implanted-annealed amorphous silicon by spectroscopic ellipsometry
}

\author{
M. Fried and T. Lohner \\ Central Research Institute for Physics, Budapest, I14, H-1525, P.O.B. 49, Hungary
}

W. A. M. Aarnink, L. J. Hanekamp, and A. van Silfhout

Faculty of Applied Physics, Twente Technical University, P.O.B. 217, 7500 AE Enschede,

The Netherlands

(Received 18 November 1991; accepted for publication 10 February 1992)

\begin{abstract}
Measuring with a spectroscopic ellipsometer (SE) in the $1.8-4.5 \mathrm{eV}$ photon energy region we determined the complex dielectric function $\left(\epsilon=\epsilon_{1}+i \epsilon_{2}\right)$ of different kinds of amorphous silicon prepared by self-implantation and thermal relaxation $\left(500{ }^{\circ} \mathrm{C}, 3 \mathrm{~h}\right)$. These measurements show that the complex dielectric function (and thus the complex refractive index) of implanted $a-\mathrm{Si}(i-a-\mathrm{Si})$ differs from that of relaxed (annealed) $a-\mathrm{Si}(r-a-\mathrm{Si})$. Moreover, its $\epsilon$ differs from the $\epsilon$ of evaporated $a-\mathrm{Si}(e-a-\mathrm{Si}$ ) found in the handbooks as $\epsilon$ for $a$-Si. If we use this $\epsilon$ to evaluate SE measurements of ion implanted silicon then the fit is very poor. We deduced the optical band gap of these materials using the Davis-Mott plot based on the relation: $\left(\epsilon_{2} E^{2}\right)^{1 / 3} \sim(E$ $\left.-E_{g}\right)$. The results are: $0.85 \mathrm{eV}(i-a-\mathrm{Si}), 1.12 \mathrm{eV}(e-a-\mathrm{Si}), 1.30 \mathrm{eV}(r-a-\mathrm{Si}) . \mathrm{We}$ attribute the optical change to annihilation of point defects.
\end{abstract}

Understanding the structure and properties of amorphous silicon ( $a-\mathrm{Si})$ is a scientific challenge of some complexity. ${ }^{1}$ The problem is that there is not a single type of $a$-Si. There are several measurements which indicate that the properties of implanted amorphous silicon ( $i-a-\mathrm{Si})$ differ significantly from those of well relaxed (annealed) $a-\mathrm{Si}$ $(r-a-\mathrm{Si}) .^{2-7}$

Additionally, we must know the optical constants of different kinds of $a$-Si to evaluate well the optical measurements. Earlier measurements ${ }^{8}$ showed that the $\epsilon$ (complex dielectric function, $\left.\epsilon=\epsilon_{1}+i \epsilon_{2}\right)$ of $i$ - $a$-Si and $r$ - $a$-Si differ from the $\epsilon$ of evaporated $a-\mathrm{Si}(e-a-\mathrm{Si})$ found in the handbooks as $\epsilon$ for $a$-Si. ${ }^{9}$ If we use this $\epsilon$ to evaluate spectroscopic ellipsometric (SE) measurements of ion implanted silicon then the fit is very poor. ${ }^{8}$ A similar thing is described by McMarr ${ }^{10}$ and Vedam, McMarr, and Narayan ${ }^{11}$ who also measured self-implanted fully amorphous silicon and tried to evaluate the spectra modeling the sample as a mixture of voids and $a$-Si prepared by low-pressure chemical vapor deposition (LPCVD). ${ }^{12}$ The model calculations resulted in a surprising $-9 \%$ void fraction. This fact also indicates that the $\epsilon$ of LPCVD $a$-Si must not be used for $i-a$-Si.

For the experiments Wacker made, $p$-type $\mathrm{Si}\langle 100\rangle$ wafers of $4-8 \Omega \mathrm{cm}$ resistivity were implanted with $S i$ ions at room temperature. The implantation conditions are shown in Table I. After implantation an adequate plasma stripping procedure ${ }^{13}$ was applied to remove a possible hydrocarbon deposition. The SE measurements were followed by annealing $\left(500^{\circ} \mathrm{C}, 3 \mathrm{~h}, \mathrm{~N}_{2}\right.$ ambient) to achieve the well relaxed state. ${ }^{2,3,7}$ (Well relaxed means that longer or higher temperature annealing does not change the optical properties of the layer.)

The ellipsometric measurements were performed with a rotating analyzer type ellipsometer in the $270-700 \mathrm{~nm}$ wavelength (4.6-1.8 eV photon energy) region at $70^{\circ}, 73^{\circ}$, and $75^{\circ}$ angle of incidence at the Twente Technical University. From these multiple-angle-of-incidence measurements we could take into account the thickness of the native oxide. The measurement error increased at the red end of the spectrum because of the light source $(75 \mathrm{~W}$ xenon lamp)-detector system and of the fact that $\cos \Delta$ was near -1 (Ref. 14) in the case of $r-a-S i$. So, we cut the spectra of this sample at $2 \mathrm{eV}$. The points at $1.96 \mathrm{eV}(633 \mathrm{~nm})$ are from measurements using a manual null ellipsometer with a $\mathrm{He}-\mathrm{Ne}$ laser light source.

To check the ellipsometric results we used Rutherford backscattering spectrometry (RBS) combined with channeling. The analyzing beam was a $2 \mathrm{MeV}^{4} \mathrm{He}^{+}$beam. We determined the thickness of the amorphous silicon layer of the as-implanted sample $(450 \mathrm{~nm})$ and the annealed one $(375 \mathrm{~nm})$. These data helped to reduce the error of evaluation.

From simulations 8 we can define an "information depth" $\left(d_{\text {inf }}\right)$ which is roughly equal to 3 OPD where OPD means optical penetration depth $(=\lambda / 4 \pi k$, where $k$ is the imaginary part of the complex refractive index). From this we can calculate $d_{\text {inf }}$ as a function of $\lambda$. The thickness of the amorphous layer was greater than $d_{\text {inf }}$ (except at the longest wavelength, near $700 \mathrm{~nm}$ ) even in the case of relaxed $a$-Si (lower $k$ and thinner layer). So, the error from the back (amorphous/crystalline) interface is negligible.

The deduced complex dielectric functions $\left(\epsilon=\epsilon_{1}\right.$

TABLE I. Implantation conditions.

\begin{tabular}{cc}
\hline \hline Energy (keV) & Dose $\left(10^{15} \mathrm{Si}^{+} / \mathrm{cm}^{2}\right)$ \\
\hline 50 & 0.25 \\
100 & 0.5 \\
150 & 1.0 \\
200 & 2.0 \\
250 & 4.0 \\
\hline
\end{tabular}




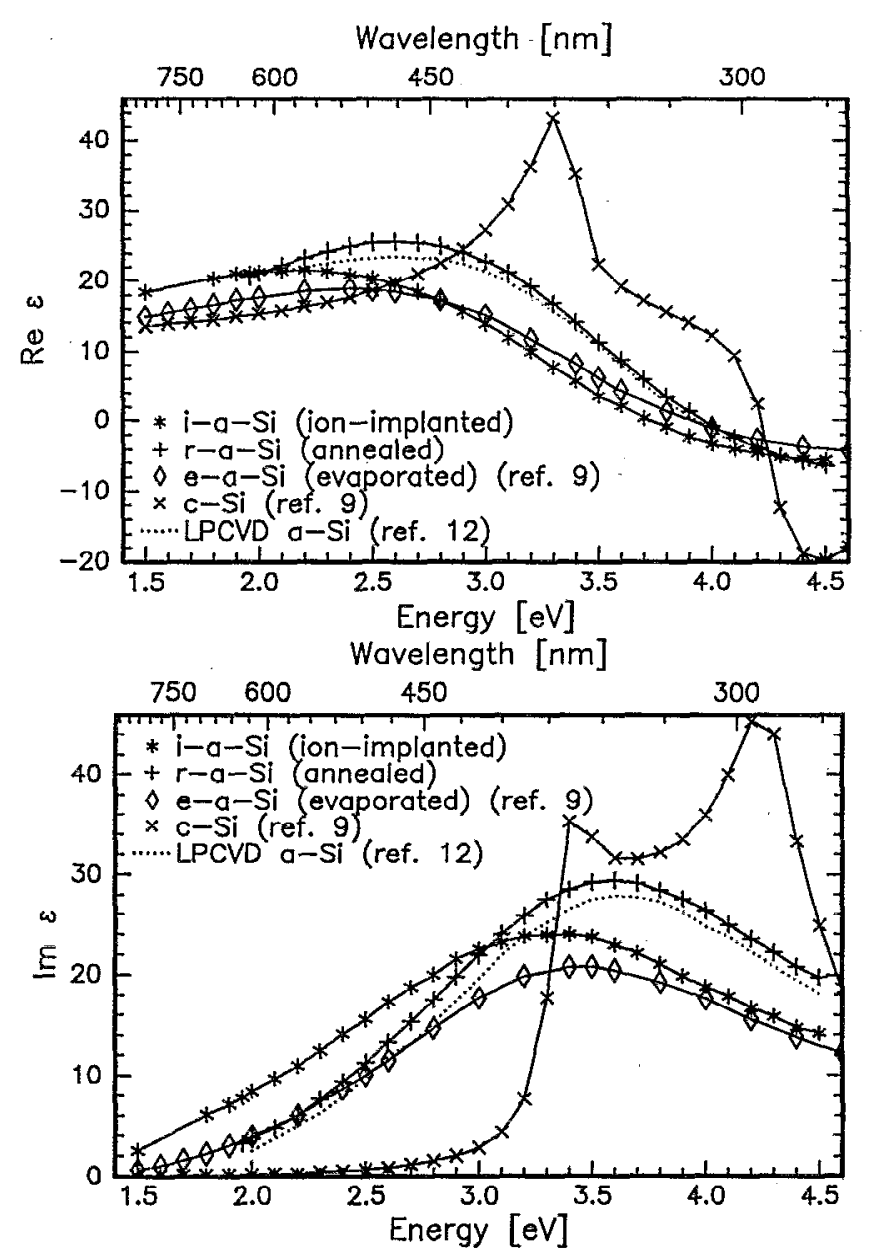

FIG. 1. Complex dielectric function of crystalline and different types of amorphous silicon. The data of $i-a-\mathrm{Si}$ at $1.5 \mathrm{eV}$ are from Ref. 18.

$\left.+i \epsilon_{2}\right)$ and refractive indices are plotted in Figs. 1 and 2. The relatively biggest difference occurs below $3 \mathrm{eV}$ in $\epsilon_{2}$. The $\epsilon_{2}$ curve of $i-a-\mathrm{Si}$ is lower and wider than the curves of others. So, the absorption of $i-a-S i$ is the highest below 3 $\mathrm{eV}$. This fact is interesting when we try to determine the optical band gap.

Davis and Mott ${ }^{15}$ deduced a relation between $\epsilon_{2}$ and $E_{\text {photon }}$ assuming two things: (a) the densities of electron energy states $N(E)$ in the valence and conduction bands near the band gap have a power function distribution $\left(E^{s}\right)$, (b) the matrix elements for interband transition associated with photon absorption are equal for all transitions. The value of $s$ can be determined by plotting $\left(\epsilon_{2} E^{2}\right)^{1 /(2 s+1)}$ against $E$. (The good $s$ value is the one that makes the relation linear.) It is observed that $s=0$ for Se, $s=\frac{1}{2}$ for $\mathrm{Ge}$, and $s=1$ for a quaternary glass $\mathrm{Si}_{0.05} \mathrm{Ge}_{0.15} \mathrm{As}_{0.25} \mathrm{Te}_{0.55}$ (Ref. 15).

It is obvious that the abovementioned relation can be used only in the energy region where the assumptions are valid. Several authors found that for different $a$-Si (glowdischarge and sputtered ${ }^{16}$ or low-energy noble gas implant$\mathrm{ed}^{17}$ ) in the $1.5-3 \mathrm{eV}$ energy range $s=1$ gives good results. We have got similar results from our measurements (Fig.
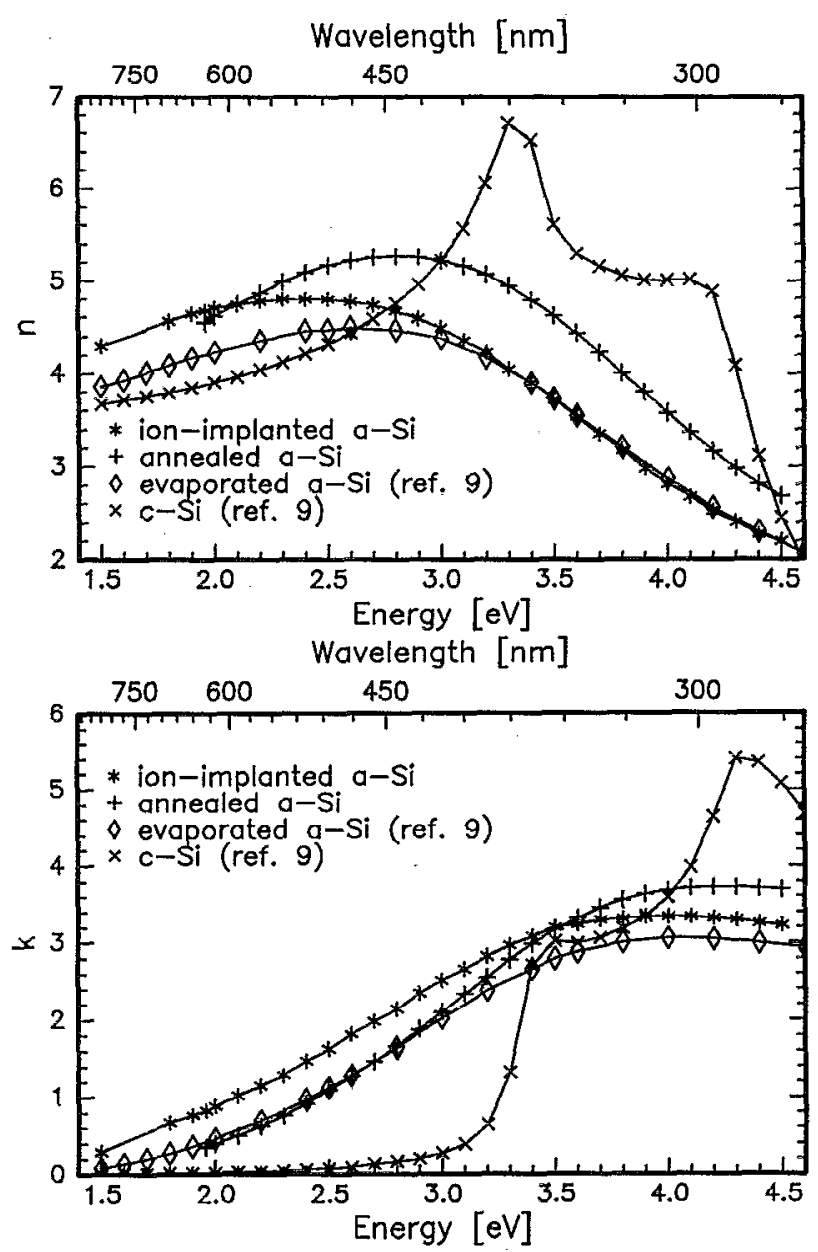

FIG. 2. Complex refractive index of crystalline and different types of amorphous silicon. The data of $i-a-S i$ at $1.5 \mathrm{eV}$ are from Ref. 18.

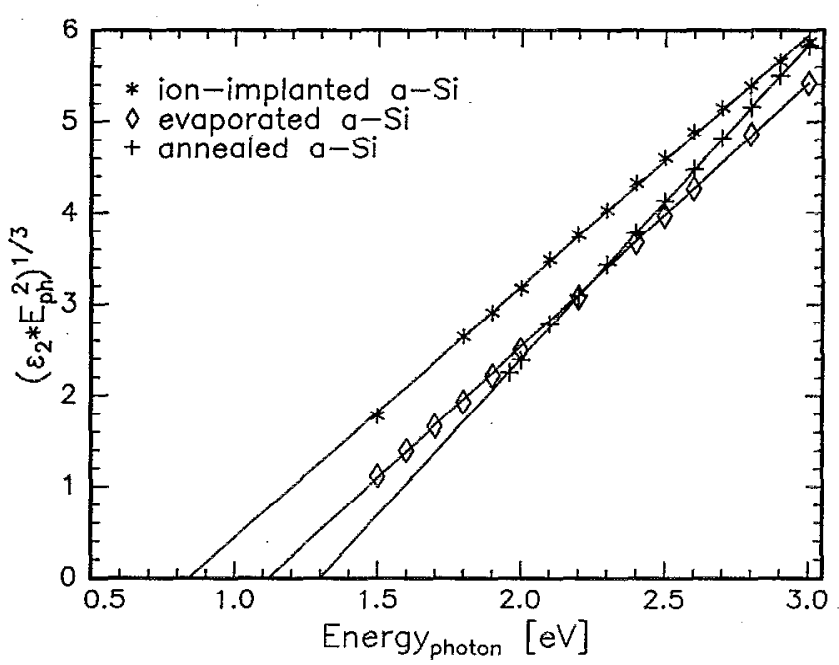

FIG. 3. Davis-Mott (Ref. 15) plot of different types of amorphous silicon based on the relation: $\left(\epsilon_{2} E^{2}\right)^{1 / 3} \sim\left(E-E_{\mathrm{g}}\right)$, where $E_{\mathrm{g}}$ is the optical band gap energy. 
TABLE II. The complex refractive index and dielectric function of implanted and relaxed (annealed) $a$-Si. The data at $1.5 \mathrm{eV}$ are from Ref. 18 .

\begin{tabular}{|c|c|c|c|c|c|c|c|c|}
\hline \multirow{2}{*}{$\begin{array}{c}E \\
(\mathrm{eV})\end{array}$} & \multicolumn{4}{|c|}{$i-a-\mathrm{Si}$} & \multicolumn{4}{|c|}{$r-a-\mathrm{Si}$} \\
\hline & $n$ & $k$ & $\epsilon_{1}$ & $\epsilon_{2}$ & $n$ & $k$ & $\epsilon_{1}$ & $\epsilon_{2}$ \\
\hline 1.5 & 4.30 & 0.29 & 18.40 & 2.49 & & & & \\
\hline 1.8 & 4.56 & 0.64 & 20.38 & 5.84 & & & & \\
\hline 1.9 & 4.64 & 0.76 & 20.95 & 7.08 & & & & \\
\hline 1.96 & 4.67 & 0.83 & 21.12 & 7.75 & 4.55 & 0.35 & 20.58 & 3.18 \\
\hline 2.0 & 4.70 & 0.89 & 21.30 & 8.37 & 4.61 & 0.40 & 21.09 & 3.69 \\
\hline 2.1 & 4.74 & 1.02 & 21.43 & 9.67 & 4.75 & 0.50 & 22.31 & 4.75 \\
\hline 2.2 & 4.78 & 1.15 & 21.52 & 10.99 & 4.87 & 0.62 & 23.33 & 6.04 \\
\hline 2.3 & 4.80 & 1.29 & 21.38 & 12.38 & 4.99 & 0.76 & 24.32 & 7.58 \\
\hline 2.4 & 4.80 & 1.47 & 20.88 & 14.11 & 5.09 & 0.92 & 25.06 & 9.36 \\
\hline 2.5 & 4.80 & 1.62 & 20.40 & 15.59 & 5.17 & 1.09 & 25.55 & 11.27 \\
\hline 2.6 & 4.77 & 1.81 & 19.48 & 17.27 & 5.22 & 1.27 & 25.63 & 13.26 \\
\hline 2.7 & 4.73 & 1.98 & 18.50 & 18.75 & 5.26 & 1.46 & 25.54 & 15.36 \\
\hline 2.8 & 4.67 & 2.14 & 17.23 & 19.98 & 5.27 & 1.66 & 25.08 & 17.49 \\
\hline 2.9 & 4.59 & 2.34 & 15.59 & 21.48 & 5.26 & 1.88 & 24.13 & 19.78 \\
\hline 3.0 & 4.49 & 2.51 & 13.86 & 22.54 & 5.22 & 2.10 & 22.84 & 21.92 \\
\hline 3.1 & 4.36 & 2.66 & 11.93 & 23.20 & 5.16 & 2.33 & 21.20 & 24.04 \\
\hline 3.2 & 4.22 & 2.82 & 9.91 & 23.83 & 5.07 & 2.55 & 19.20 & 25.86 \\
\hline 3.3 & 4.05 & 2.96 & 7.64 & 23.97 & 4.95 & 2.78 & 16.77 & 27.52 \\
\hline 3.4 & 3.90 & 3.08 & 5.72 & 24.02 & 4.79 & 2.98 & 14.06 & 28.55 \\
\hline 3.5 & 3.72 & 3.20 & 3.57 & 23.78 & 4.62 & 3.17 & 11.29 & 29.29 \\
\hline 3.6 & 3.54 & 3.24 & 2.03 & 22.94 & 4.44 & 3.32 & 8.69 & 29.48 \\
\hline 3.7 & 3.35 & 3.30 & 0.33 & 22.11 & 4.23 & 3.45 & 5.99 & 29.19 \\
\hline 3.8 & 3.18 & 3.31 & -0.84 & 21.05 & 4.01 & 3.55 & 3.48 & 28.47 \\
\hline 3.9 & 2.98 & 3.34 & -2.27 & 19.91 & 3.80 & 3.63 & 1.26 & 27.59 \\
\hline 4.0 & 2.81 & 3.34 & -3.26 & 18.77 & 3.58 & 3.68 & -0.72 & 26.35 \\
\hline 4.1 & 2.67 & 3.33 & -4.00 & 17.81 & 3.37 & 3.71 & -2.41 & 25.00 \\
\hline 4.2 & 2.52 & 3.32 & -4.64 & 16.71 & 3.17 & 3.72 & -3.79 & 23.58 \\
\hline 4.3 & 2.40 & 3.30 & -5.13 & 15.84 & 2.98 & 3.72 & -4.96 & 22.17 \\
\hline 4.4 & 2.27 & 3.25 & -5.41 & 14.75 & 2.81 & 3.70 & -5.79 & 20.79 \\
\hline 4.5 & 2.20 & 3.22 & -5.56 & 14.19 & 2.68 & 3.69 & -6.43 & 19.78 \\
\hline
\end{tabular}

3). Plotting $\left(\epsilon_{2} E^{2}\right)^{1 / 3}$ against $E$ and extrapolating to zero we get $E_{g}$ (optical band gap energy). The results are: 0.85 $\mathrm{eV}(i-a-\mathrm{Si}), 1.12 \mathrm{eV}(e-a-\mathrm{Si}), 1.30 \mathrm{eV}(r-a-\mathrm{Si})$.

Roorda et al. ${ }^{7}$ recently investigated different kinds of $a$-Si. They characterized $i-a-\mathrm{Si}, r-a-\mathrm{Si}$, ion implanted (reimplanted) well relaxed amorphous $\mathrm{Si}(i-r-a-\mathrm{Si})$, and ion implanted (with the same ion and dose) crystalline $\mathrm{Si}$ ( $i$ $c$-Si) by widely different techniques such as calorimetry, Raman spectroscopy, atomic density, and impurity diffusion measurements. They concluded that the change (structural relaxation) during thermal treatment in $i$ - $a$-Si is mediated by annihilation of network defects. This picture (in terms of annihilation of point defects) is well established by the abovementioned comparative experiments of $i-a-\mathrm{Si}, i-r-a-\mathrm{Si}$, and $i-c-\mathrm{Si}$. The results of our measurements support this explanation, i.e., the optical change can be attributed to the annihilation of point defects. The $i-a$-Si is the most defected material, so there is the largest number of states in the band gap. This fact explains that the $E_{g}$ is the lowest and the absorption is the highest below $3 \mathrm{eV}$ in the case of $i-a-\mathrm{Si}$.

We show the complex dielectric function of LPCVD made $a$-Si (Ref. 12) in Fig. 1 (dotted curve). It is interesting (but not surprising) that this curve is very close to the curve of $r-a-\mathrm{Si}$. $\left(r-a-\mathrm{Si}\right.$ was annealed at $500^{\circ} \mathrm{C}$ and the
LPCVD a-Si was made at $600^{\circ} \mathrm{C}$.)

In summary, we determined the complex dielectric function of different kinds of amorphous silicon prepared by self-implantation and thermal relaxation. (The results are summarized in Table II. The data at $1.5 \mathrm{eV}$ are from Ref. 18.) These measurements show that the complex dielectric function (so the complex refractive index) of implanted $a$-Si differs from $\epsilon$ of relaxed (annealed) $a-\mathrm{Si}$. Moreover, its $\epsilon$ differs from the $\epsilon$ of evaporated $a$-Si found in the handbooks as $\epsilon$ for $a-\mathrm{Si}$. So, we must use $\epsilon$ of implanted $a$-Si to evaluate rightly optical measurements of implanted silicon samples.

We deduced the optical band gap of these materials using the Davis-Mott plot. The resulted $E_{g}: 0.85 \mathrm{eV}$ ( $i-a$ $\mathrm{Si}), 1.12 \mathrm{eV}(e-a-\mathrm{Si}), 1.30 \mathrm{eV}(r-a-\mathrm{Si})$. These results support the explanation which attributes the optical change to annihilation of point defects. The identification of these defects needs further investigation.

One of the authors (M.F.) is grateful to NUFFIC (Netherlands organization for international cooperation in higher education) for the scholarship at the Twente Technical University.

${ }^{1}$ J. M. Poate, in Amorphous Si and Related Materials, Vols. A and B, edited by A. Fritsche (World Scientific, New Jersey, 1989), p. 149.

${ }^{2}$ J. E. Fredrickson, C. N. Waddell, W. G. Spitzer, and G. K. Hubler, Appl. Phys. Lett. 40, 172 (1982).

${ }^{3}$ W. G. Spitzer, G. K. Hubler, and T. A. Kennedy, Nucl. Instrum. Methods 209/210, 309 (1983).

${ }^{4}$ M. Fried, T. Lohner, G. Vizkelethy, E. Jároli, G. Mezey, and J. Gyulai, Nucl. Instrum. Methods B 15, 422 (1986).

${ }^{5}$ M. Fried, T. Lohner, E. Jároli, G. Vizkelethy, E. Kótai, J. Gyulai, A. Biró, J. Ádám, M. Somogyi, and H. Kerkow, Nucl. Instrum. Methods B 19/20, 577 (1987).

${ }^{6}$ S. Roorda, S. Doorn, W. C. Sinke, P. M. L. O. Scholte, and E. van Locnen, Phys, Rev. Lett. 62, 1880 (1989).

${ }^{7}$ S. Roorda, J. S. Custer, W. C. Sinke, J. M. Poate, D. C. Jacobson, A. Polman, and M. Spaepen, Nucl. Instrum. Methods B 59/60, 344 (1991).

${ }^{8}$ M. Fried, T. Lohner, W. A. M. Aarnink, L. S. Hanekamp, and A. van Silfhout, J. Appl. Phys. 71, 2835 (1992).

${ }^{9}$ Handbook of Optical Constants of Solids, edited by E. D. Palik (Academic, Orlando, 1985), and references therein; $c$-Si: D. E. Aspnes and A. A. Studna, Phys. Rev. B 27, 985 (1983); a-Si: D. T. Pierce and W. E. Spicer, Phys. Rev. B 5, 3017 (1972).

${ }^{10}$ P. J. McMarr, PhD thesis, The Pennsylvania State University, 1985.

${ }^{11}$ K. Vedam, P. J. McMarr, and J. Narayan, Appl. Phys. Lett. 47, 339 (1985)

${ }^{12}$ B. G. Bagley, D. E. Aspnes, A. C. Adams, and C. J. Mogab, Appl. Phys. Lett. 38, 56 (1981).

${ }^{13}$ T. Lohner, G. Mezey, E. Kótai, F. Pászti, A. Manuaba, and J. Gyulai, Nucl. Instrum. Methods 209/210, 615 (1983).

${ }^{14}$ R. M. A. Azzam and N. M. Bashara, Ellipsometry and Polarized Light (North-Holland, New York, 1977).

${ }^{15}$ E. A. Davis and N. F. Mott, Philos. Mag. 22, 903 (1970).

${ }^{16}$ R. H. Klazes, M. H. Van Den Broek, J. Bezemer, and S. Radelaar, Philos. Mag. B 45, 377 (1982).

${ }^{17}$ A. H. M. Holtslag, PhD thesis, Twente Technical University, 1986; A. H. M. Holtslag and A. van Silfhout, Phys. Rev. B 38, 10556 (1988).

${ }^{18}$ M. Simard-Normandin, I. S. Few, A. Kalnitsky, R. Normandin, C. Martel, and Y. Beauliu, J. Electrochem. Soc. 134, 1794 (1987). 